\title{
PARTISIPASI MASYARAKAT DALAM IMPLEMENTASI PROGRAM KOTAKU / PNPM DI KECAMATAN CIAWI
}

\section{PUBLIC PARTISIPATION ON IMPLEMENTATION OF KOTAKU/PNPM PROGRAM IN CIAWI BOGOR MUNICIPALITY}

\author{
Dadan Rohimat' ${ }^{\text {, Rita Rahmawati², G. Goris Seran }}{ }^{3}$ \\ ${ }^{1}$ Jurusan Ilmu Administrasi Negara Fakultas Ilmu Sosial dan Ilmu Politik Universitas Djuanda, Jl. \\ Tol Ciawi No.1, Kotak Pos 35 Bogor 16770 \\ ${ }_{2}^{2} J u r u s a n$ Ilmu Administrasi Negara Fakultas Ilmu Sosial dan Ilmu Politik Universitas Djuanda, Jl. \\ Tol Ciawi No.1, Kotak Pos 35 Bogor 16770 \\ ${ }^{3}$ Jurusan Ilmu Administrasi Negara Fakultas Ilmu Sosial dan Ilmu Politik Universitas Djuanda, Jl. \\ Tol Ciawi No.1, Kotak Pos 35 Bogor 16770
}

(Diterima oleh Dewan Redaksi : 01-08-2017)

(Dipublikasikan oleh Dewan Redaksi : 01-10-2017)

\begin{abstract}
The background of this research based on constitution article 27 paragraph 2 which states that "every citizen is entitled to work and means appropriate for humanity". Several steps are taken by a government in implementing this law such as the national program of community empowerment like KOTAKU/PNPM. Generally, there are contemporary issues in development such as Human Development Index (HDI), Poverty , Justice and Social Equality and accordingly there are strategic issues in the Bogor area such as Human Development Index is still low, marked by unemployment and poverty rate is still high and although Bogor has sufficient natural resources and competitive, but not yet been explored optimally. Thefore, it is important to discuss the participation of the program KOTAKU / PNPM as a form of community involvement to resolve these issues. KOTAKU Program use synergy platform the collaboration of local government and other stakeholders in the district and community-based infrastructure development to accelerate the handling of urban slum problems.

Research methodology used is quantitative descriptive, technique of data collection and data analysis use primary and secondary data based on observation technique, the questionnaire and interview, and then processed into the form of figures to do statistic calculation to draw conclusion. The sampling technique used is proportional random sampling in accordance to Solvin's formula, and obtained samples of 100 respondents, with reference to productive ages.

Based on the research it can be concluded that based on the calculation on those dimensions of public participation in Ciawi district has a value of 3.72 and intepreted as "good" category. With the conditions of Ciawi district which is so vast, potential large enough of religious communities, but still high poverty rate and many things to be improved and could not
\end{abstract}


be separated from public participation in developing their areas. But there are several things must be done to increase, among others as follow: (1) Socialization should be increased, that intention and purposes can be implemented and in accordance with the target. (2) Optimalitazing society organizations in the each area/Village. And (3) Budget transparancy is needed to maintain of public trust.

Keywords : Participation, Implementation, Program

\begin{abstract}
ABSTRAK
Latar belakang penelitian ini berdasarkan UUD 1945 pasal 27 ayat 2 yang berbunyi: “ Setiap warga negara berhak atas pekerjaan dan penghidupan yang layak bagi kemanusian ". Langkah yang diambil oleh pemerintah dalam melaksanakan undang-undang tersebut adalah melakukan beberapa hal, diantaranya yaitu Program Nasional Pemberdayaan Masyarakat KOTAKU. Memperhatikan isu-isu yang berkembang sekarang ini antara lain tentang human development index (IPM), kemiskinan (poverty), keadilan dan kesetaraan sosial (social equality). Adapun isu-isu strategis di wilayah kabupaten Bogor, di antaranya: indeks pembangunan manusia masih rendah, dengan ditandai angka pengangguran dan angka kemiskinan masih tinggi dan Kabupaten Bogor memiliki sumber daya alam yang memadai dan kompetitif, namun belum diolah secara maksimal. Untuk itu perlu dibahas partisipasi masyarakat dalam program KOTAKU/PNPM sebagai bentuk keterlibatan masyarakat dalam menjawab isu-isu tersebut. Pada Program KOTAKU digunakan sinergi platform kolaboratif yaitu antara pemerintah daerah dan pemangku kepentingan lain di kabupaten/kota dan Pembangunan Infrastruktur Berbasis Masyarakat, untuk mempercepat penanganan perkotaan kumuh.

Metode penelitian ini menggunakan metode kuantitatif deskriptif, teknik pengumpulan data dan analisa data menggunakan data primer dan sekunder dengan teknik observasi, kuesioner dan wawancara, yang selanjutnya diolah kedalam bentuk angka-angka untuk dilakukan perhitungan statistik untuk mendapatkan kesimpulan. Pengambilan sampel dilakukan secara random atau acak proforsional sesuai rumus Solvin, dan diperoleh sampel sebanyak 99.89 dibulatkan menjadi 100 orang, dengan mengacu pada usia produktif.

Berdasarkan hasil penelitian ditemukan hasil perhitungan indikator- partisipasi masyarakat Kecamatan Ciawi memperoleh nilai 3.72 dengan kategori Baik. Dengan kondisi kecamatan ciawi yang begitu luas, potensi yang cukup besar dengan masyarakat yang agamis, namun masih tinggi angka kemiskinan dengan indikator masih banyak yang perlu dilakukan perbaikan, namun pada program ini tidak lepas dari peranserta atau partisipasi masyakarat dalam membangun wilayahnya. Namun ada beberapa hal yang harus di tingkatkan diantaranya sebagai berikut : (1) Sosialisasi program harus lebih ditingkatkan, agar maksud dan tujuan dapat dilaksanakan dan sesuai dengan sasaran, (2) Mengoptimalkan organisasi-organisasi masyarakat yang berada di masing-masing desa / kelurahan, dan (3)Transparansi anggaran sangat di butuhkan, demi menjaga kepercayaan publik.
\end{abstract}

Kata kunci : Partisipasi, Implementasi, Program 
Dadan Rohimat, 2017, Partisipasi Masyarakat Dalam Implementasi Program KOTAKU / PNPM di Kecamatan Ciawi. Jurnal Governansi. 


\section{PENDAHULUAN}

Setiap warga Negara berhak untuk hidup secara sejahtera baik lahir maupun batin, mendapatkan tempat tinggal, dan memperoleh lingkungan hidup yang baik dan sehat, serta pelayanan kesehatan. Hal tersebut menunjukkan bahwa hak tempat tinggal dengan lingkungan yang layak merupakan hak dasar yang harus dijamin pemenuhannya oleh Pemerintah sebagai penyelenggara Negara. Memperhatikan permasalahan yang berkembang sekarang ini antara lain tentang kemiskinan (poverty), keadilan dan kesetaraan sosial (social equality), ketahanan pangan, marginalisasi dan eksploitasi, pemerataan pembangunan.

Dalam relevansinya dengan ungkapan tersebut, maka berdasarkan hasil pengamatan terhadap situasi dan kondisi wilayah, kebijakan pemerintah diberbagai tingkatan, atensi dan interest para pemangku kepentingan, dapat diungkapkan mengenai isu-isu strategis sebagai berikut:

1. Memiliki sumberdaya penduduk yang cukup potensial dengan strata angka Indeks Pembangunan Manusia (IPM) berada pada level medium dari 40 kecamatan yang berada di Kabupaten Bogor, tetapi angka pengangguran dan angka keluarga miskin masih cukup banyak.

2. Memiliki keanekaragaman sumberdaya alam yang cukup potensial dan kompetitif untuk usaha budi daya perhutanan, perkebunan, pertanian, pariwisata, perdagangan dan jasa, serta permukiman, namun belum dapat diberdayakan secara optimal.

Masih banyak wilayah yang belum tersentuh oleh pemerintah pusat serta keterlibatan masyarakat terhadap program masih kurang, hal ini terlihat pada pembangunan Rumah Tidak Layak Huni (RTLH), Jumlah RLTH tahun 2013 sebanyak 59.359 unit. Target pada tahun 2014 sebanyak 10.000 unit (RTLH), sedangkan sisanya direncanakan dalam 4 tahun berikutnya sesuai kapasitas pembiayaan pada masing-masing tahun Anggaran, di willayah Ciawi penanganan Rutilahu periode 2009-2016 adalah 2.124 dan yang sudah di Realisasikan 1.335 Rumah, sisa 789 rumah, Jadi pencapaian sekitar $62.85 \%$.

Pada pertengahan tahun 2016 PNPM berubah nama menjadi KOTAKU (kota tanpa kumuh), yang menekankan pada inprastruktur. Kehidupan yang layak merupakan hak semua warga Negara Indonesia, tujuan dari penghidupan yang layak adalah sebagai penunjang bagi pembangunan sumber daya manusia yang produktif secara social dan ekonomi dalam meningkatkan kesejahteraan masyarakat. Untuk mencapai tujuan tersebut maka perlu diselenggarakan upaya pembangunan yang berkesinambungan yang terpadu dan terarah, termasuk diantaranya pembangunan pada daerahdaerah yang kurang tertata dan terkesan kumuh.

Untuk menangani permaslahan pemukiman kumuh di wilayah perkotaan, Direktorat Jenderal Cipta Karya Kementerian Pekerjaan Umum dan Perumahan Rakyat (PUPR) menyelenggarakan Program Kota Tanpa Kumuh (KOTAKU) di 269 Kabupaten/Kota dengan pendanaan melalui World Bank dan Islamic Development Bank, APBN, APBD dan Masyarakat. Menurut data dari BPS kawasan permukiman kumuh saat ini mencapai luas 38.431 hektar, 23.473 ha diantaranya berada di wilayah perkotaan, dan 11.957 ha berada diwilayah perdesaan. "Khusus untuk wilayah perkotaan, Direktorat Jenderal Cipta Karya menyelenggarakan berbagai program penanganan permukiman kumuh salah satunya adalah Program KOTAKU".

Penanganan permukiman yang kumuh merupakan tantangan untuk pemerintah kabupaten/kota. Sebab disutau sisi menjadi permasalahan utama, juga sebagai pilar penyangga sector ekonomi kabupaten/kota, dasar dari cita-cita bangsa. Dengan memperhatikan tantangan- 
tantangan yang ada, pemerintah harus melakukan penanganan perumahan dan permukiman kumuh sebagai target Nasional, yang sudah tertuang dalam Rencana Pembangunan Jangka Menengah Nasional (RPJMN) tahun 2015-2019.

Melihat kondisi kecamatan dengan luas kira-kira 2.555.071 Ha. Jumlah jiwa yang tersebar di wilayah Kecamatan Ciawi sebanyak 99.399 jiwa terdiri dari pria sebanyak 51.395 (51.71\%) dan wanita sebanyak 48.004 ( $48.29 \%$ ) seks rasio 107:100 , banyaknya rumah tangga 25.232 keluarga dan jumlah rata-rata anggota keluarga 3,9 jiwa/keluarga. Kondisi sosial ekonomi sebagian besar relatif masih rendah, dengan sumber pendapatan penduduk kebanyakan bekerja menjadi petani $(38,89 \%)$, pedagang $(23,58 \%)$, dan buruh $(29,86 \%)$ umumnya bekerja pada sektor jasa, perdagangan dan industri di luar wilayah.

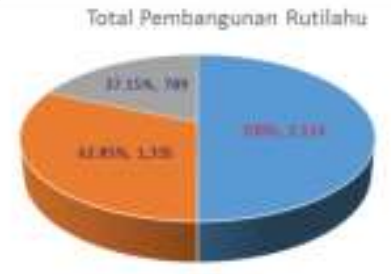

\section{Diagram 2. Realisasi Pembangunan Rutilahu}

\section{MATERI DAN METODE}

\section{Konsep Atau Teori Yang Relevan}

Hetifah (dalam Handayani 2006:39) berpendapat bahwa "Partisipasi adalah pelibatan orang secara sukarela tanpa adanya tekanan dan jauh dari kepentingan eksternal".

Sedangkan Menurut Histiraludin (dalam Handayani 2006:39-40) disebutkan bahwa "Partisipasi lebih ditekankan pada alat sehingga dimaknai sebagai pelibatan masyarakat secara aktif dalam keseluruhan proses kegiatan, sebagai media penumbuhan kohesifitas diantara masyarakat, pemerintah juga menggalang timbulnya rasa memiliki dan tanggung jawab pada program yang dilakukan".
Cohen dan Uphoff dalam Astuti D (2011: 61-63) membedakan patisipasi menjadi empat jenis, (1) partisipasi pada pengambilan keputusan. (2), partisipasi pada pelaksanaan. (3) partisipasi pada pengambilan pemanfaatan. Dan (4), partisipasi pada evaluasi.

Pertama, partisipasi pada pengambilan keputusan. Partisipasi ini berkaitan dengan menentukan alternatif dengan masyarakat yang berkaitan yaitu melalui ide atau gagasan yang menyangkut kepentingan umum. Adapun wujud partisipasi ini antara lain seperti ikut menyumbangkan gagasan pemikiran, melalui kehadiran saat rapat, memberikan tanggapan atau penolakan terhadap program yang ditawarkan.

Kedua, partisipasi pada pelaksanaan yaitu meliputi upaya menggerakkan sumber daya keuangan, kegiatan-kegiatan administratif, koordinasi serta penjabaran program.

Ketiga, partisipasi pada pengambilan manfaat. Partisipasi dalam konteks ini tidak lepas dari pelaksanaan yang telah dicapai baik dari sisi kualitas (output kegiatan) maupun kuantitas (dilihat dari presentase keberhasilan program).

Keempat, partisipasi dalam hal evaluasi. Partisipasi dalam evaluasi berkenaan dengan pogram yang sudah direncanakan. Partisipasi memiliki tujuan untuk mengetahui sejauhmana ketercapaian suatu program yang telah direncanakan sebelumnya.

Berdasarkan definisi-definisi di atas maka dapat disimpulkan bahwa partisipasi adalah kegiatan yang didalamnya terdapat keterlibatan individu atau kelompok dalam pencapaian tujuan juga adanya pembagian kewenangan atau tanggung jawab bersama.

Sedangkan pengertian implementasi kebijakan publik adalah proses kegiatan administratif yang dilakukan setelah adanya keputusan yang ditetapkan/disetujui. Kegiatan ini terletak di antara perumusan kebijakan dan Implementasi Kebijakan evaluasi kebijakan mengandung logika yang bersifat topdown, yang berarti dari atas ke bawah/ 
alternatif menginterpretasikan -. Alternatif masih abstrak atau bersfat alternatif makro atau mikro-beton "(Prof. h. Tachjan2006: 25) Menurut Teori George C. Edwards III (1980). Dalam pandangannya Edwards III menyebutkan bahwa implementasi kebijakan dipengaruhi oleh empat faktor, yaitu: (1) komunikasi, (2) sumberdaya, (3) disposisi, dan (4) struktur birokrasi. Keempat faktor tersebut juga saling berhubungan satu sama lain. (Subarsono, 2005:90).

\section{Kerangka Berpikir}

Dari beberapa teori yang sudah dijabarkan di atas saya lebih tertarik dengan pendapat Cohen dan Uphoff dalam Astuti D (2011: 61-63) membedakan partisipasi menjadi empat jenis, yaitu (1), partisipasi dalam pengambilan keputusan. (2), partisipasi dalam pelaksanaan. (3), partisipasi dalam pengambilan pemanfaatan. (4), partisipasi dalam evaluasi, sedangkan dalam implementasi saya menggunakan teori Edward III dengan 4 indikator yaitu, Komunikasi, Sumber Daya, Struktur organisasi dan pelaksanaan.

Partisipasi:

1. Pengambilan keputusan

2. Pelaksanaan

3. Pemamfaatan

4. Evaluasi

Implementasi:
1. Komunikasi
2. Sumber Daya
3. Pelaksanaan
4. Struktur Organisasi

\section{Operasional Variable}

Untuk memberikan kemudahan dalam memenuhi variable yang akan diukur dalam penelitian ini, perlu dirumuskan pengertian dan istilah yang akan digunakan untuk memperoleh batasan yang jelas dan untuk memudahkan dalam menentukan indikatornya. Dalam penelitian ini peneliti menggunakan dua variable yaitu partisipasi dan implementasi.

\begin{tabular}{|c|c|c|}
\hline Variable & Dimensi & Indikator \\
\hline \multirow[t]{14}{*}{ Partisipasi } & \multirow[t]{4}{*}{$\begin{array}{ll}\text { 1. } & \text { Pengambil } \\
\text { an } \\
\text { keputusan }\end{array}$} & $\begin{array}{l}\text { 1. Terlibat dalam } \\
\text { pengambilan } \\
\text { keputusan }\end{array}$ \\
\hline & & 2. $\begin{array}{l}\text { Kehadiran dalam } \\
\text { rapat }\end{array}$ \\
\hline & & $\begin{array}{ll}\text { 3. } & \text { Menyumbang } \\
\text { Gagasan }\end{array}$ \\
\hline & & $\begin{array}{l}\text { 4. Menentukan } \\
\text { alternatf Keputusan }\end{array}$ \\
\hline & & $\begin{array}{l}\text { 5. } \begin{array}{l}\text { Diskusi, penolakan } \\
\text { Program }\end{array}\end{array}$ \\
\hline & \multirow{3}{*}{$\begin{array}{l}\text { 2. Pelaksanaan } \\
\text { (Implementasi } \\
\text { ) }\end{array}$} & 1. Menyumbang Dana \\
\hline & & \\
\hline & & 2. Kontribusi Tenaga \\
\hline & \multirow[t]{3}{*}{$\begin{array}{l}. \\
\text { Pemamfaatan }\end{array}$} & $\begin{array}{l}\text { 1. Pemamfaatan Output } \\
\text { / hasil } \\
\text { pembangunan }\end{array}$ \\
\hline & & $\begin{array}{l}\text { 2. } \begin{array}{r}\text { Partisipasi dalam } \\
\text { pemamfaatan }\end{array} \\
\end{array}$ \\
\hline & & $\begin{array}{l}\text { 3. } \begin{array}{l}\text { Keberhasilan } \\
\text { program }\end{array} \\
\end{array}$ \\
\hline & \multirow[t]{3}{*}{ 4. Evaluasi } & $\begin{array}{ll}\text { 1. } & \text { Monitoring } \\
& \text { Pelaksanaan } \\
& \text { Program / Kegiatan } \\
\end{array}$ \\
\hline & & $\begin{array}{l}\text { 2. Evaluasi dari hasil } \\
\text { pembangunan }\end{array}$ \\
\hline & & $\begin{array}{l}\text { Evaluasi terhadap } \\
\text { Masalah-masalah } \\
\text { yang timbul }\end{array}$ \\
\hline \multirow[t]{7}{*}{$\begin{array}{l}\text { Implementa } \\
\text { si }\end{array}$} & \multirow[t]{2}{*}{$\begin{array}{l}\text { 1. Komunika } \\
\text { si }\end{array}$} & $\begin{array}{l}\text { 1. Sosialisasi Tujuan } \\
\text { dan mamfaat }\end{array}$ \\
\hline & & 2. Pemahaman Tujuan \\
\hline & \multirow{3}{*}{$\begin{array}{l}\text { 2. Sumber } \\
\text { daya }\end{array}$} & 1. Dukungan Staff Ahli \\
\hline & & 2. Dukungan anggaran \\
\hline & & $\begin{array}{ll}\text { 3. Dukungan Sarana \& } \\
\text { Prasarana }\end{array}$ \\
\hline & 3. Disposisi & $\begin{array}{ll}\text { 1. } & \text { Komitmen aparat } \\
\text { 2. } & \text { Dukungan aparat }\end{array}$ \\
\hline & $\begin{array}{ll}4 . & \text { Struktur } \\
& \text { Birokrasi } \\
\end{array}$ & $\begin{array}{l}\text { 1. Karakteristik, Pola- } \\
\text { pola hubungan }\end{array}$ \\
\hline
\end{tabular}

\section{Pendekatan Penelitian}

Penelitian ini berpendekatan kuantitatif, dimana proses penulisan usulan penelitian, proses pengambilan data di lapangan, analisa data dan membuat kesimpulan data sampai dengan penulisannya dengan menggunakan aspek pengukuran, perhitungan, rumus dan kepastian data numerik.

\section{Metode Penelitian}

Penelitian ini menggunakan metode deskriptif dengan bertujuan untuk membuat pencanderaan/ lukisan/ deskripsi terkait fakta-fakta dan sifat-sifat 
suatu populasi atau daerah tertentu secara sistematik, faktual dan teliti (Ginting, 2008:55).

\section{Teknik Analisa Data \\ Populasi dan Sampel}

Menurut Sugiyono

(2007:72)

populasi adalah wilayah generalisasi yang terdiri atas objek atau subjek yang mempunyai kualitas dan karakteristik tertentu yang ditetapkan peneliti untuk dipelajari kemudian ditarik kesimpulannya. Populasi dalam penelitian ini adalah Masyarakat Kecamatan Ciawi yang berjumlah 99.399 jiwa, dengan usia angkatan kerja produktif berumur antara 16-60 tahun hingga mencapai 43.230 jiwa (43.49\%). Sampel adalah bagian dari populasi yang karakteristiknya dianggap mampu mewakili keseluruhan populasi. Untuk menentukan jumlah sampel yang akan diambil digunakan rumus Slovin (Ginting, 2008:132),

\section{Teknik Penarikan Sampel}

Dalam metode ini, cara pemilihan sampel dilakukan secara acak (random). Demikian pula dengan jumlah sampel minimum, harus dihitung secara matematis berdasarkan probabilitas. Untuk mendapatkan sampel yang benar benar representatif terhadap populasi penelitian, penarikan sampel dilakukan secara proposional dengan menggunakan simple random sampling dengan ukuran sampel ditentukan berdasarkan rumus SOLVIN (Ginting: 2008).

\section{Teknik Analisis Data}

Penelitian ini menggunakan teknis analisis data yaitu menganalisa data-data yang diperoleh sesuai dengan permasalah penelitian, dan data-data yang telah terkumpul melalui, studi lapangan, Quistioner, studi pustaka serta dokumentasi, yang selanjutnya kita kalkulasi untuk mendapatkan jawaban dari permasalahan yang ada.

Analisa data yaitu suatu cara mengelola, mengklasifikasi data sehingga sampai pada kesimpulan tertentu. Untuk memperoleh analisis data dan penarikan kesimpulan maka sampling juga menggunakan perhitungan statistic sederhana yaitu mentransformasikan data kualitatif menjadi kuantitatif, dengan menggunakan perhitungan WMS (Weight Means Scored) yaitu melakukan pembobotan setiap pilihan jawaban. Untuk menafsirkan hasil jawaban dari angket maka dilakukan pembuatan table kriteria penilaian dari hasil angket dengan skala interval sebagai berikut:

$\mathrm{i}=\mathrm{skt}-\mathrm{skr}=5-1=0.8$

$$
\mathrm{v} \quad 5
$$

Pemberian score menurut seperti ini akan mendapatkan variasi jawaban yang bergerak dari 1 sampai 5 sehingga diperoleh interval antara 1 dengan yang lain yaitu 0,80 . Sehingga diperoleh kriteria penapsiran sebagai berikut:

Tabel 3.4

Kriteria penafsiran

\begin{tabular}{ll}
\hline Interval Score & Kriteria \\
\hline $4,20-5$ & Sangat Baik \\
\hline $3,40-4,19$ & Baik \\
\hline $2,60-3,39$ & Cukup Baik \\
\hline $1,80-2,59$ & Kurang Baik \\
\hline $1-1,79$ & Sangat Tidak \\
& Baik \\
\hline
\end{tabular}

Sumber: Sugiono,2012

Perolehan angka penafsiran WMS sebagai berikut:

$\sum M=\underline{f(x)}$

$n$

Keterangan: $\mathrm{M}=$ perolehan angka penafsiran

$$
\begin{aligned}
& \mathrm{f}=\text { Pembobotan skala nilai } \\
& \sum=\text { Jumlah } \\
& \mathrm{n}=\text { Jumlah sampel penelitian }
\end{aligned}
$$

\section{Hasil dan Pembahasan}

Untuk mendapatkan jawaban sejauhmana partisipasi masyarakat dalam implementasi program KOTAKU atau PNPM sebagai berikut : 


\section{Rekapitulasi Variabel Partisipasi Masyarakat}

\begin{tabular}{|c|l|l|l|}
\hline No & \multicolumn{1}{|c|}{ Indikator } & Skor & Penafsiran \\
\hline 1 & $\begin{array}{l}\text { Pengambilan } \\
\text { Keputusan }\end{array}$ & 3.69 & Baik \\
\hline 2 & $\begin{array}{l}\text { Pelaksanaan / } \\
\text { implementasi }\end{array}$ & 3.50 & Baik \\
\hline 3 & Pemafaatan & 4.06 & Baik \\
\hline 4 & Evaluasi & 3.74 & Baik \\
\hline JUMLAH & & 3.74 & Baik \\
\hline
\end{tabular}

\section{Rekapitulasi Variabel Implementasi}

\begin{tabular}{|c|l|c|c|}
\hline No & \multicolumn{1}{|c|}{ Dimensi } & skor & Penafsiran \\
\hline 1 & Komunikasi & 3.47 & Baik \\
\hline 2 & Sumberdaya & 3.45 & Baik \\
\hline 3 & $\begin{array}{l}\text { Disposisi / } \\
\text { Attitude }\end{array}$ & 3.83 & Baik \\
\hline 4 & $\begin{array}{l}\text { Struktur } \\
\text { Birokrasi }\end{array}$ & 4.06 & Baik \\
\hline JUMLAH & & 3.70 & Baik \\
\hline
\end{tabular}

\section{Rekapitulasi Variabel Partisipasi Masyarakat Dan Implementasi}

\begin{tabular}{|c|l|l|l|}
\hline No & \multicolumn{1}{|c|}{ Variabel } & Skor & Penafsiran \\
\hline 1 & $\begin{array}{l}\text { Partisipasi } \\
\text { Masyarakat }\end{array}$ & 3.74 & Baik \\
\hline 2 & $\begin{array}{l}\text { Implementasi } \\
\text { Kebijakan }\end{array}$ & 3.70 & Baik \\
\hline JUMLAH & & 3.72 & Baik \\
\hline
\end{tabular}

Berdasarkan tabel diatas rekapitulasi Variabel Partisipasi dan Implementasi Kebijakan adalah $\mathbf{3 . 7 2}$ dengan nilai tersebut maka dikategorikan Baik, bahwa responden menyatakan hubungan antara pemerintah kecamatan/ desa, organisasi lainnya saling terintegrasi (Program jangka jangka pendek, menengah dan jangka panjang ) di realisasikan melalui program-program pemerintah seperti PNPM/KOTAKU, Ecovillage, dimana semua kegiatan tersebut saling terhubung dan tidak terjadinya tumpang tindih, jadi program saling mengisi demi mencapai tujuan yang telah ditentukan oleh pemerintah daerah sesuai dengan Renstra (Rencana Strategis ).
Hambatan-hambatan yang ada dalam pelaksanaan Program di Kecamatan Ciawi

Didalam menjalankan program-program yang telah diagendakan, ada beberapa hambatan-hambatan sehingga mempengaruhi implementasi / pelaksanaan program tersebut, diantaranya :

1. Kebiasaan masyarakat Kecamatan Ciawi yang tidak mau mandiri, kesadaran masyarakat yang kurang , tidak memahami pentingnya peran serta masyarakat dalam pembangunan di Kecamatan Ciawi dan menganggap kemajuan desa dilakuan oleh kepala desa dan staffnya.

2. Anggaran yang tidak memadai sehingga pembangunan mengalami perlambatan, hal ini terlihat dari program yang telah di capai berkisar $62 \%$, aspek keuangan memberikan gambaran yang jelas bahwa masyarakat masih bertumpu pada alokasi kegiatan infrastruktur, dibanding dengan pembiayaan seperti pengembangan usaha dan ekonomi kecil-menengah.

3. Kondisi Kecamatan Ciawi yang tersebar di pelosok desa mengakibatkan kurang efektifnya informasi yang disampaikan ke masyarakat

4. Kemampuan staff desa yang tidak sesuai dengan keahlian mengakibatkan lambat dalam segi administrasi ( pelayanan ataupun sosialisasi )

5. Ketersediaan sumberdaya, teknologi masih belum memadai.

6. Pemberdayaan masyarakat masih kurang, hal ini terlihat dari kehadiran dan kepedulian dari masyakarat masih sedikit serta pandangan masyarakat yang hanya sebagai penerima mamfaat, belum mejadikan dia sebagai Perencana, Pelaksana dan pemelihara, dan sedikit menciptakan kader peduli organisasi. 


\section{Upaya-upaya yang dilakukan dalam menghadapi hambatan-hambatan}

Adapun upaya yang dilakukan kecamatan atau desa dalam menghadapi hambatanhambatan tersebut, diantaranya:

1. Peranserta masyarakat Kecamatan Ciawi dalam segala aspek, baik pembangunan maupun kegiatan sosial yang bertujuan memajukan Kecamatan Ciawi, dalam bentuk di ikutsertakannya BPD, BKM, LPM, Ecovillage dalam pembangunan dan perawatan sarana air bersih dan infra struktru lainnya oleh masyarakat Kecamatan Ciawi.

2. Mengingat kondisi Kecamatan Ciawi yang tersebar di pelosok, maka kepala desa melakukan kordinasi rutin dengan tingkat RT, RW dan Kepala Dusun serta tokoh masyarakat, di samping itu kepala desa juga melakukan jum'at keliling untuk melihat kondisi masyarakat dan masukan dari masyarakat Kecamatan Ciawi.

3. Pemberdayaan masyarakat lebih ditingkatkan dengan mengoptimalkan peranserta lembaga yang ada dimasyarakat dan mengikutsertakan perusahan yang ada di wilayah Ciawi, dalam hal ini adalah program Chanelling, dan berkordinasi dengan dinas lainnya.

4. Melakukan perbaikan dan perombakan dalam proses administrasi di Kecamatan Ciawi, dimulai dari pelayanan sampai persetujuan, contohnya untuk pengeluaran anggaran tidak hanya bendahara, Sekdes yang bertanda tangan tapi juga harus ditandatangani oleh kepala desa, dan waktu tempuh pelayanan lebih dipercepat dengan di kuranginya birokrasi yang tidak perlu. Dalam hal perubahan ini kepala desa juga melakukan training terhadap staff desa dengan tujuan menaikan kemampuan personal.

\section{KESIMPULAN DAN SARAN Kesimpulan}

Berdasarkan hasil perhitungan mengenai dimensi-dimensi partisipasi masyarakat Kecamatan Ciawi memperoleh nilai $\mathbf{3 . 7 2}$ dengan kategori Baik. Dengan kondisi kecamatan ciawi yang begitu luas, potensi yang cukup besar dengan masyarakat yang agamis, namun masih tinggi angka kemiskinan dengan indicator masih banyak yang perlu dilakukan perbaikan, namun pada program ini tidak lepas dari peranserta atau partisipasi masyakarat dalam membangun wilayahnya. Kegiatan pengelolaan PNPM / KOTAKU dibentuk dengan mempertimbangkan input yang terdiri dari aspek pemberdayaan sebagai alat control pembangunan di kecamatan Ciawi.

Penggunaan teknologi tepat guna untuk mengatasi masalah lingkungan, penyederhanaan prosedur, aturan dan mekanisme, kebijakan dan aspek motivasi tergantung dari aktor atau lembaga yang ada di wilayah ciawi, tidak terlepas dari peranserta pemerintah daerah.

\section{Saran}

Di dalam melaksanakan program yang akan dilakukan, diperlukan beberapa perbaikan diataranya adalah:

\section{Untuk Kecamatan}

Keterlibatan masyarat sangat diperlukan untuk menjalankan program dengan tujuan agar kecamatan ciawi menjadi masyarakat yang sebelumnya tidak berguna menjadi berguna, berdaya menjadi berdaya, jadi perlu adanya penangan khusus untuk masyakarat yang kurang mampu, dengan cara memaksimalkan kinerja aparat kecamatan, dan harus bersinergi antara pihak Kecamatan, Desa, tokoh masyarakat dan masyarakat itu sendiri, memotivasi kepala daerah dalam hal ini kecamatan dan Desa untuk peningkatan program pemberdayaan yang dapat menggerakan masyarakat selaku penerima mamfaat. 


\section{Untuk Masyarakat/warga}

Diperlukannya kesadaran dan kemauan warga masyarakat untuk berpartisipasi dan bekerjasama dengan aparat kecamatan/ desa untuk pembangunan dan pengembangan wilayah agar tercipta masyarakat yang sejahtera, aman dan damai.

\section{DAFTAR PUSTAKA}

Agustino, Leo. (2006). Dasar-Dasar Kebijakan Publik. Alfabeta: Bandung.

Cohen Bruce J; tanpa tahun, Sosiologi Suatu Pengantar, penerbit Rineka Cipta.

Dunn, William. (2003). Pengantar Analisis Kebijakan Publik (Edisi Kedua, Cetakan Kelima). Gadja Mada University: Yogyakarta.

Ekowati, Lilik Roro Mas. (2009). Perencanaan, Implementasi dan Evaluasi Kebijakan atau Program (Suatu Kajian Teoritis dan Praktis). Pustaka Cakra: Surakarta.

Isbandi, Rukminto Adi. (2007). Perencanaan Partisipatoris Berbasis Aset Komunitas: Dari Pemikiran Menuju Penerapan. Depok: Fisip UI press.

Nugroho, Riant. (2003). Kebijakan Publik Formulasi, Implementasi, Evaluasi. PT. Elex Media Komputindo: Jakarta.

Soerjono Soekanto; (2009), Sosiologi Suatu Pengantar, Edisi Baru, Rajawali Pers Jakarta.

Subarsono, AG. (2008). Analisis Kebijakan Publik (Konsep, Teori dan Aplikasi). Cetakan Ketiga. Pustaka Pelajar: Yogyakarta.

Supriady, Deddy dan Riyadi. (2005). Perencanaan Pembangunan Daerah. Jakarta: SUN.

Suryono, Agus. (2001). Teori dan Isi Pembangunan. Malang: Universitas Negeri Malang. UM Press. 